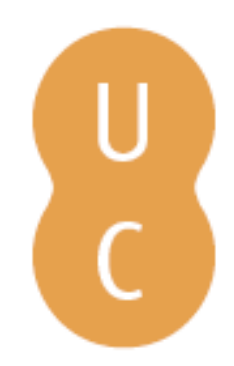

\title{
pombalina
}

\section{El banquete traicionero en las Vidas de Plutarco}

Autor(es): $\quad$ Muñoz Gallarte, Israel

Publicado por: Imprensa da Universidade de Coimbra; Centro de Estudos Clássicos e Humanísticos

URL

persistente: URI:http://hdl.handle.net/10316.2/32001

DOI: DOI:http://dx.doi.org/10.14195/978-989-8281-17-3_22

Accessed : $\quad$ 26-Apr-2023 15:36:56

A navegação consulta e descarregamento dos títulos inseridos nas Bibliotecas Digitais UC Digitalis, UC Pombalina e UC Impactum, pressupõem a aceitação plena e sem reservas dos Termos e Condições de Uso destas Bibliotecas Digitais, disponíveis em https://digitalis.uc.pt/pt-pt/termos.

Conforme exposto nos referidos Termos e Condições de Uso, o descarregamento de títulos de acesso restrito requer uma licença válida de autorização devendo o utilizador aceder ao(s) documento(s) a partir de um endereço de IP da instituição detentora da supramencionada licença.

Ao utilizador é apenas permitido o descarregamento para uso pessoal, pelo que o emprego do(s) título(s) descarregado(s) para outro fim, designadamente comercial, carece de autorização do respetivo autor ou editor da obra.

Na medida em que todas as obras da UC Digitalis se encontram protegidas pelo Código do Direito de Autor e Direitos Conexos e demais legislação aplicável, toda a cópia, parcial ou total, deste documento, nos casos em que é legalmente admitida, deverá conter ou fazer-se acompanhar por este aviso.

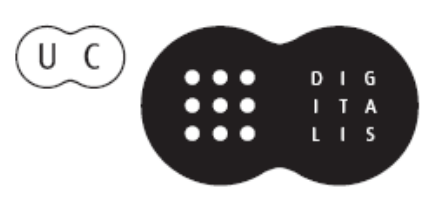




\section{Symposion and Philanthropia in Plutarch}

\section{José Ribeiro Ferreira, Delfim Leão Manuel Troster e Paula Barata Dias (eds.)}

IMPRENSA DA UNIVERSIDADE DE COIMBRA 


\title{
El banquete traicionero en las Vidas de Plutarco
}

\author{
Israel Muñoz Gallarte \\ Universidad de Groningen
}

\begin{abstract}
The aim of this study is to explore the topic of the death during the banquet in Plutarch's Vitae. The motif is frequent in classical literature and various authors provide us with numerous examples and the question arises whether we are dealing with a literary topos or rather with historical facts. Can we find a structural relationship between the texts? By means of an analysis of Alexander, Arquias-Pelopidas and others shorter quotations we will try to determine how Plutarch saw these events and why the conjurers chose this occasion to fulfil their objective.
\end{abstract}

En una obra, ya clásica, de Nicolae I. Barbu, Biographies de Plutarque ${ }^{1}$, se puso de relieve la importancia que en las Vidas adquieren las muertes y los tipos de muerte descritos por Plutarco. De este modo, el paso a la otra vida, minuciosamente narrado por su autor, parece estar en una interesante simbiosis con las hazañas realizadas por sus protagonistas. En este sentido, el de Queronea afirma acerca de la muerte de Pericles: 'A $\lambda \lambda \grave{\alpha} \tau \alpha \tilde{v} \tau \alpha \mu \grave{\varepsilon} \nu$ ǐ $\sigma \omega \varsigma$

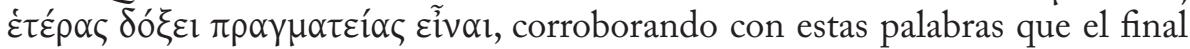
de la vida de los héroes es "una confirmación de sus hechos gloriosos", en el que "Plutarco añade, a veces, sus pensamientos acerca de la vida del personaje o sobre la vida humana en general" 2 .

Algunas de las muertes que describe Plutarco, puntos finales de las vidas ilustres de sus protagonistas, se desarrollan en un escenario concreto, el banquete. En las siguientes páginas se analizarán estos casos de traición y asesinato, documentados por Plutarco en las Vidas, con la intención de explicar su significado y la opinión que merecen a su autor.

\section{Introducción: ¿eera el banquete un evento lúdico?}

El banquete en el mundo greco-romano ha sido tradicionalmente descrito como "el encuentro privado que, con ocasión de una cena refinada, reúne a una serie de protagonistas de los ambientes de la política o del pensamiento"3, en cuya atmósfera íntima de juego y esparcimiento los personajes disfrutan del vino, la comida, la música y la conversación.

Sin embargo, a pesar de la definición anteriormente expuesta, Plutarco no sólo concibe el banquete como un momento de diversión, sino que también afirma categóricamente en sus Quaestiones romanae que la mesa es sagrada-

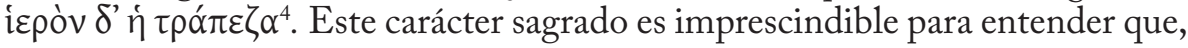

${ }^{1}$ N. I. BARBu, 1933.

${ }^{2}$ Idem, p. 15.

${ }^{3}$ Quizá reminiscencia del círculo aristocrático en el que tiene su origen el simposio, cf. G. Paul, 1991, p. 161.

${ }^{4}$ Plu., Mor. 279E. Plutarco inserta esta información al tratar por qué una mesa no puede encontrarse nunca vacía. 
aunque se trata de un contexto lúdico donde los comensales pueden divertirse, ciertas acciones de mal gusto, crueles u homicidas pueden corromper las reglas del convite, ocasionando diversas consecuencias que sufrirán quienes las infringieron.

Los banquetes relatados en las $V i t a e^{5}$ ofrecen múltiples ejemplos en los que se rompen sus características intrínsecas, el ambiente lúdico-festivo o su carácter religioso. Sirva de ejemplo el mítico enfrentamiento surgido entre lapitas y centauros, a propósito de las bodas de Pirítoo ${ }^{6}$, o el anuncio de Catón de su próximo suicidio, cuando en palabras de Plutarco $^{7}$ :

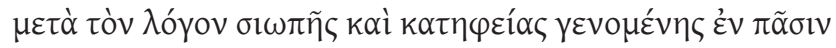

"tras su discurso, hubo un silencio y tristeza en todos".

Otro caso de mayor crudeza resulta el destino que corre el cadáver de Craso, asesinado por los partos, cuya cabeza, lanzada por Silaces en medio del banquete, sirvió como atrezo de una improvisada representación de Bacantes, embellecida por los versos del poeta Eurípides ${ }^{8}$.

Igualmente son numerosos los casos de complots fallidos en las Vidas de Plutarco, documento interesante para conocer las causas que llevan a elegir el banquete como lugar adecuado para este tipo de acciones. Tanto es así que, para el autor de las Vidas, una de las más importantes razones para declinar una invitación es la posibilidad de que uno de los comensales pueda atentar contra la vida de otro:

- Medea elige matar con uno de sus venenos a Teseo, quien se hacía pasar por extranjero, durante la comida que celebraba su llegada a Atenas. Pero Egeo,

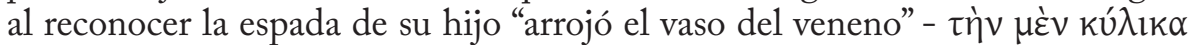

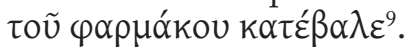

- Parisátide, hija extramatrimonial de Artajerjes I, pone fin a la vida de su nuera, Estatira, quien, sin la advertencia de ninguno de los comensales, come del ave envenenada que le ofrece su suegra ${ }^{10}$.

- Alejandro V de Macedonia, tras intentar asesinar a Demetrio durante un banquete en Dio, terminó su vida unos días después a la salida de otro convite, a manos de los soldados enviados por Demetrio, sufriendo el mismo final que

${ }^{5}$ Frances B. Titchener explica la existencia de una dualidad, positiva y negativa, en los banquetes descritos por Plutarco; cf. F. B. Titchener, 1999, pp. 491-2.

${ }^{6}$ Plu., Thes., 30. 3-4.

${ }^{7}$ Plu., Cat. Mi., 67. Acerca de la posible relación existente entre la muerte de Catón y la de Sócrates, cf. T. E. Duff, 1999, pp. 144-5.

${ }^{8}$ Plu., Crass., 33.1-4. Cf. N. Simões Rodrigues, en este mismo volumen, p. 232.

${ }_{9}^{9}$ Plu., Thes., 12.3-4. Cf. D. Romero GonzÁlez, en este mismo volumen, pp. 257-58.

10 Plu., Art., 19; Dinon, FGrH 690 F 15b; Ctes., FGrH 688 F 29b. Eludimos abordar en la presente comunicación los casos de asesinato en el banquete mediante la utilización de veneno, tratados por D. Romero González en este mismo volumen, pp. 255-61. También, cf. N. Simões Rodrigues, en este mismo volumen, pp. 231-32. 
él había urdido ${ }^{11}$.

- También Otón se vio envuelto en un enfrentamiento, en el que si no hubiera sido por sus ruegos e incluso lágrimas, un grupo de exaltados pretorianos habría dado muerte a ochenta senadores invitados a cenar al palacio del emperador, ya que los soldados creían que de ese modo acababan con los enemigos del César ${ }^{12}$.

- Arato y Antonio consiguieron librarse del intento de asesinato de Nicocles ${ }^{13}$ y Menas, respectivamente ${ }^{14}$.

Finalmente, el banquete puede ser el escenario para reconocer futuros intentos de asesinato, como el de Lucio Terencio contra su compañero de tienda, Pompeyo, el cual, enterado de lo que iba a ocurrir, mientras finge con Terencio durante la cena, advierte a la guardia de las malas intenciones del simposiasta, lo que acabará con éste ${ }^{15}$.

Tras observar estos primeros ejemplos se puede adelantar ya que, lejos de la idílica definición anteriormente aportada del banquete greco-romano, éste, en la práctica, era una celebración llena de luces y sombras, en la que la traición y el homicidio acompañaban al vino y a las conversaciones amistosas.

\section{Muertes en banquete}

Más interesantes para el tema que aquí se trata son los banquetes en los que se lleva a cabo el peor acto traicionero, la muerte de uno de los convidados ${ }^{16}$. En este caso, el simposio ofrece unas posibilidades inmejorables para llevar a cabo un asesinato. Así lo explica Plutarco en la Vida de Pelópidas ${ }^{17}$ :

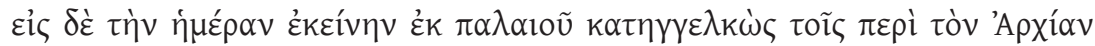

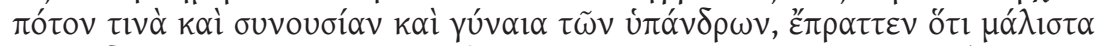

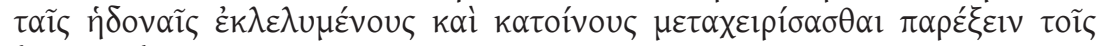

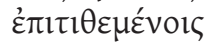

desde hacía tiempo, había invitado para aquel día a Arquias y a los suyos a una reunión para beber con mujeres casadas, se ocupó de dejarlos muy debilitados por los placeres y beodos para entregárselos a los atacantes.

Plutarco detalla en las Vitae tres de estos asesinatos: el de Arquias en la Vida de Pelópidas, el de Clito en el relato de la Vida de Alejandro y la muerte de Sertorio. Las tres escenas resultan interesantes por los elementos comunes

${ }^{11}$ Plu., Demetr., 36.4-12; el mismo final, en semejantes circunstancias, sufre Neoptólemo, a manos de Pirro, cf. Plu., Pyrrh., 5.7-14. Cf. D. Romero GonzÁlez, en este mismo volumen, pp. 256-257.

${ }^{12}$ Plu., Oth., 3.4.

${ }^{13}$ Plu., Arat., 6.4-7.1.

${ }^{14}$ Plu., Ant., 32.3.8; App., BC, 5.73, 308-11; Dio 48.38.

${ }^{15}$ Plu., Pomp., 3.2.

${ }^{16}$ Son numerosos los casos de complots fallidos; cf. F. B. Titchener, 1999, pp. 492-3.

${ }^{17}$ Plu., Pel., 9.4. 
que el biógrafo ofrece ${ }^{18}$. Junto a estas tres, también se analizarán otras breves noticias de la misma temática recogidas por Plutarco.

\subsection{La muerte de Arquias}

La muerte de Arquias se inserta en un contexto concreto: el complot contra los magistrados impuestos por Esparta en Tebas. La traición de Pelópidas era un acto sabido y fácil de predecir, porque la oposición del pueblo tebano era manifiesta y conocida, incluso por algunos de los aliados de Arquias. No obstante, fue la bebida, junto con otros disfrutes del banquete, la que hizo que el tirano tomara la mala decisión de dejar para el día siguiente la carta en que se le ofrecían los datos exactos de la conjura que se urdía contra él. Dice Plutarco:

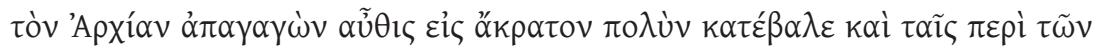

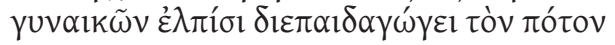

(scil. Fílidas) llevándose de nuevo a Arquias le sirvió buena cantidad de vino puro y entretenía el festín con la esperanza de mujeres.

Así, Arquias y los suyos, beodos y perdidos, no pueden oponerse al ataque de Pelópidas y los demás conjurados que, disfrazados de mujeres, entran en el banquete armados y acaban asesinando a los comensales en la misma sala o durante su huída a las casas vecinas.

El levantamiento de Pelópidas, tras una noche de enfrentamientos contra la guardia, termina finalmente con el regreso de los exiliados desde Atenas y la victoria del bando tebano.

Un caso semejante es el crimen de estado que Euriclidas cometió contra los Éforos, por mandato de Cleomenes ${ }^{19}$. La imagen del homicida, al igual que la de Pelópidas, fue para Plutarco la del libertador de la patria, lo cual garantiza una justificación ética, según la moral del biógrafo, al acto cometido.

Sin embargo, no todos los magnicidios son éticamente admisibles, como se relata en la Vida de Cimón ${ }^{20}$, en la que el autor relata cómo el joven Damón Peripoltas de Queronea, importunado por un jefe de cohorte que se había enamorado de él, se vio obligado a asesinarlo durante un sacrificio. Posteriormente, los magistrados romanos condenaron a muerte a éste y a sus compañeros de complot, lo que produjo que los conjurados también acabaran con éstos, eligiendo como escenario del crimen una cena.

En esta cita aparecen elementos comunes a la muerte de Arquias, a saber, los conjurados se camuflan, tiznándose los rostros con hollín, y "beben vino

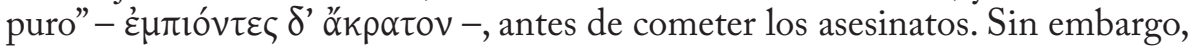

${ }^{18}$ En la cronología relativa establecida por C.P. Jones, las Vidas de Pelópidas y Marcelo ocuparían una posición entre la II y la IV; Sertorio y Eumenes ocuparían un lugar difícil de determinar, o bien II-IV, o bien XVI-XXIII; finalmente, Alejandro y César, serían XIII-XIV; cf. C.P. Jones, 1966, p. 68.

${ }^{19}$ Plu., Cleom., 7-8.

${ }^{20}$ Plu., Cim., 1.5. 
el final de Damón fue distinto al de Pelópidas y Euriclidas, pues sus crueles desmanes por la región de Queronea, que no buscaban acabar con un gobierno injusto para la polis, sino un bien personal, lo llevaron a ser asesinado en el gimnasio de la ciudad.

Como se puede ver en estos ejemplos, Plutarco no muestra en todas las ocasiones una visión negativa de las muertes en banquete, sino que simplemente las trata como ocasiones favorables para cometer un asesinato. Son la moral y las intenciones de los protagonistas las que le confieren al magnicidio traicionero un valor positivo o negativo para la comunidad.

\subsection{La muerte de Clito}

El final de $\mathrm{Clito}^{21}$, famoso ya en tiempos de Plutarco por los numerosos autores que lo habían tratado, comienza con la exculpación de Alejandro, pues, en palabras del autor, este desgraciado hecho se produjo por dos elementos que no suelen faltar en un banquete de esta índole, la cólera y la embriaguez:

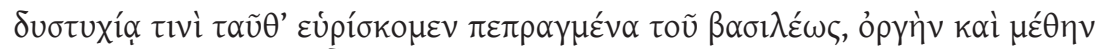

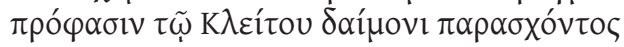

descubrimos que esta acción fue producto de una desgracia del rey, cuya cólera y embriaguez fueron el pretexto del que se sirvió el mal démon de Clito.

Con esto Plutarco deja fuera de dudas quién es el culpable de la muerte de Clito, el vino ${ }^{22}$, no siéndolo, en ningún caso, el protagonista de su Vita que, en último término, debe ofrecer un ejemplo de comportamiento moral.

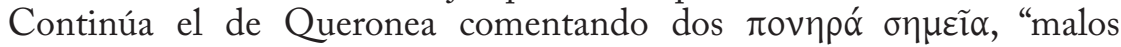
augurios", que anuncian la próxima muerte de Clito: "tres de las reses sobre las que había vertido las libaciones lo siguieron” y la extraña visión que se presentó a Alejandro en sueños.

Ya en el banquete, el autor describe cómo se había bebido gran cantidad de vino y se cantaban canciones de escarnio contra los vencidos. La mezcla de ambos ingredientes, sumados a la osadía de Clito, fueron los detonantes de una airada discusión entre Alejandro y su general, en la que se pone en duda la valentía de Clito, se bromea con la divinidad del soberano, se exalta el origen macedonio del ejército frente a la barbarie de los pueblos sometidos y, finalmente, se acusa de filobárbaro a Alejandro. Éste, sin poder contener su ira, le arroja unas manzanas a Clito y, gracias a la entrada de la guardia, se consigue evitar el enfrentamiento directo de los contendientes. No obstante, la posterior entrada de Clito en la sala del banquete da la oportunidad a Alejandro de robar una lanza a uno de sus guardias y clavársela en el costado al general macedonio.

${ }^{21}$ Plu., Alex., 50-51. Cf. N. Simões Rodrigues, en este mismo volumen, pp. 231-232.

${ }^{22}$ Acerca de la importancia de esta bebida en la Vida de Alejandro, cf. C. Alcalde Martín, 1999, pp. 90-1. No obstante, también se debe tener en cuenta la distinta interpretación que

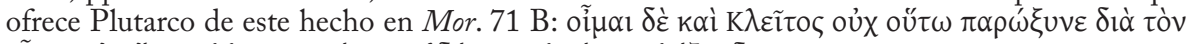

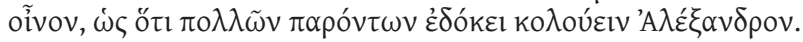


Alejandro, apesadumbrado por sus actos, intenta suicidarse con la misma lanza, pero, tras el impedimento de su propia guardia, se marcha a sus aposentos en los que pasa la noche lamentándose.

A la mañana siguiente, los macedonios consiguen tranquilizarle relativamente, pero éste no volverá a ser el mismo: $\tau$ ò $\delta$ ' $\tilde{\eta} \theta$ o

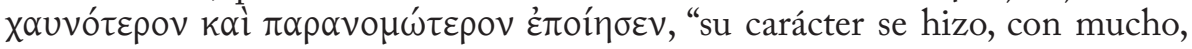
más vanidoso e injusto".

\subsection{La muerte de Sertorio}

Un tercer ejemplo de homicidio en un banquete es el de $\mathrm{Sertorio}^{23}$, un relato que Plutarco desarrolla ofreciendo, al igual que en el de Clito, gran cantidad de detalles:

Comienza Plutarco planteando la situación en la que el protagonista de la $V i t a$ se encontraba en aquel momento, sin un futuro claro, con la mayoría de los hispanienses ${ }^{24}$ "dominados por la envidia" y con un Sertorio que, habiendo

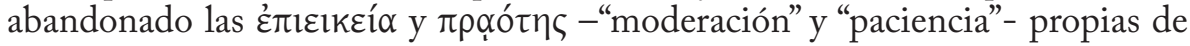
su carácter, ha cometido una gran injusticia contra los hijos de los nobles íberos que estudiaban en Osca.

En esta situación, que presagia el final de Sertorio, un grupo de conjurados hispanienses con Perpenna a la cabeza decide llevar a término un complot que ya había planeado desde hacía tiempo: la muerte de Sertorio en un banquete.

El plan debe acelerarse por la falta de discreción de Manlio, de modo que, inmediatamente, hacen llegar a Sertorio una carta en la que le proponen celebrar una supuesta victoria militar.

Sertorio, antes del banquete, se encuentra curiosamente, al igual que Clito, realizando un sacrificio en agradecimiento de la buena noticia recibida.

Posteriormente, describiendo ya la preparación del convite de Perpenna, Plutarco se permite un pequeño inciso para explicar cómo a Sertorio le gustaban

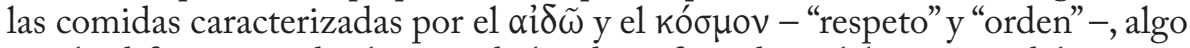
que lo diferencia radicalmente de las desenfrenadas celebraciones del ejército macedonio. En ese momento, según el autor, Perpenna busca un "inicio de

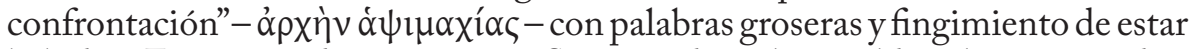
bebidos. Esta actitud provocó que Sertorio diera la espalda a los conjurados, circunstancia que es aprovechada por éstos para acabar con el general25.

Un elemento curioso que ha suscitado una duda en la crítica es el siguiente: la elección del banquete para llevar a cabo un asesinato se explica por sus características esenciales antes mencionadas, es decir, se trata de un ambiente privado de esparcimiento, en el que la víctima no debe esperar el ataque. Por tanto, no se entiende por qué Perpenna y los conjurados provocaron a Sertorio, lo que, sin duda, le pondría alerta. Konrad escribió literalmente: "a happy victim is more easily dispatched than a resentful one who may be on edge and, hence, on guard". Ante esta duda, el comentarista, basándose en el paralelo de

\footnotetext{
${ }^{23}$ Plu., Sert., 26. Cf. N. Simões Rodrigues, en este mismo volumen, p. 232.

${ }^{24}$ Romanos del bando Sertoriano, afincados en Hispania.

${ }^{25}$ Este mismo hecho aparece resumido por Plutarco en Pomp. 20. 3-4.
} 
la muerte de Cicerón, propone que provocando la ira de Sertorio se intenta legitimar el homicidio, al demostrar el carácter despótico de éste. Ernst Badian supone que Perpenna y los conjurados partían de un plan preconcebido, según el cual darían muerte a Sertorio en la confusión de un enfrentamiento ${ }^{26}$. Quizá la respuesta a esta posible incongruencia se encuentre en la estructura que Plutarco articula a la hora de describir las muertes en banquete.

\section{Conclusiones}

Si se analizan los relatos de las muertes de Arquias, Clito y Sertorio, se observa que los tres siguen en paralelo detalles clave:

- Los trágicos asesinatos son predecibles antes de ocurrir el suceso, en el caso de Arquias por una carta que anunciaba la próxima conjura, en el de Clito mediante visiones en sueños y en el de Sertorio por la traicionera actividad de sus aliados en Hispania.

- Los dos últimos banquetes se celebran por victorias, una cierta, la otra ficticia, de los ejércitos macedonio e hispaniense, respectivamente.

- Clito y Sertorio celebran un sacrificio de agradecimiento a los dioses antes del banquete.

- En todos los relatos se produce, previo a la muerte, un violento enfrentamiento verbal y físico, en los que se vitupera el mal uso del vino y de las palabras ${ }^{27}$.

- Finalmente, aquellos que han cometido el homicidio cruel en un banquete sufren unas consecuencias no deseadas, a excepción de Pelópidas y los suyos. El futuro de Perpenna queda pronto cercenado por Pompeyo y su ejército; mientras que el final de Alejandro, según el relato de Plutarco se vuelve a relacionar, por última vez con el vino: $\alpha u ̉ \tau o ̀ v ~ \pi u \rho \varepsilon ́ \tau \tau o v \tau \alpha ~ v \varepsilon \alpha v i k \tilde{\omega} \varsigma$, $\delta ı \psi \eta ́ \sigma \alpha \nu \tau \alpha \delta \dot{\varepsilon} \sigma \varphi \delta^{\delta} \rho \alpha, \pi \imath \varepsilon \tilde{\mathcal{i}} v$ oĩvov, "le sube una alta fiebre y, teniendo una gran sed, bebe vino"28.

De este modo se puede entender que Plutarco, al escribir los relatos de homicidios en los banquetes, parte de unos elementos comunes que, de manera consciente o inconsciente, estructuran la escena. En esta construcción el autor parece hacer uso de unos hechos históricos y tradicionales que organiza y relata para que cumplan sus propios fines morales ${ }^{29}$. Así, compone vívidas escenas de las que se extraen claras conclusiones: Plutarco, en este tipo de asesinatos, advierte la posibilidad de que el banquete puede perder sus características

${ }^{26}$ Cf. C.F. Kon Rad, 1994, p. 212.

${ }^{27}$ También paralelo al relato de la muerte de Clito es el enfrentamiento causado por la denuncia de alcoholismo de Alejandro a su padre, Filipo; cf. F.B. Titchener, 1999, p. 492.

${ }^{28}$ Cf. Plu., Alex. 75. Cf. G. Paul, 1991, p. 162.

${ }^{29}$ Resulta interesante observar los textos paralelos a los relatos de Plutarco. Sirvan de ejemplo acerca de la muerte de Sertorio los textos de Salustio, Hist. III,81; Livio, Per.,96; Apiano, B.C.I., 113,528; Diodoro XXXVII,22; Veleyo II,31,1; Amiano Marcelino 30,1,23; Eutropio 6,1,3; Orosio V,23,13. Especialmente curioso resulta el documento de Apuleyo, en el que se afirma: "(scil. Perpenna) tras haberle emborrachado a él (scil. Sertorio) y a su guardia, que rodeaba la sala del banquete, le dio muerte al acabar la fiesta”. 
esenciales, para tornarse en una acción trágica y traicionera, cuando se conjugan

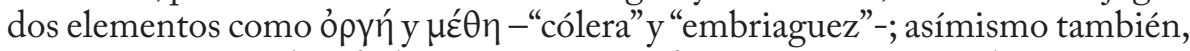
que quien, aprovechando las circunstancias de este microcosmos, las rompe, en primer lugar, no conseguirá aquello que busca con su acto cruel y, en segundo lugar, acabará sufriendo un final igualmente funesto -lo que parece responder a la concepción religiosa que del banquete defendía Plutarco-. El ejemplo de la muerte de Arquias ofrece un final distinto, puesto que, a diferencia de los anteriores, es un magnicidio legítimo: se trata de acabar con el poder dictatorial, lo que da carta blanca moral a los conjurados.

A la luz de los contextos analizados se constata que Plutarco estaba muy interesado en describir las luces y las sombras que rodeaban los banquetes ${ }^{30}$. La inversión de aquellos elementos, que se suponen consustanciales al simposio, como el ambiente de juego y esparcimiento, unido a su religiosidad, sirven a Plutarco de exempla para advertir al lector del cruel final que puede sufrir, si no observa los sucesos premonitorios, anteriores al banquete, o si bebe en exceso. Una buena solución la encuentra el de Queronea en el comportamiento de Epaminondas, basado en la austeridad y discreción, pues "tal tipo de comida no deja sitio a la traición" ${ }^{31}$.

\section{Bibliografía CITADA}

Alcalde Martín, C., "Usos indebidos del vino", in J.G. Montes et al. (eds.), Plutarco, Dioniso y el vino. Actas del VI Simposio Español sobre Plutarco (Cádiz, 14-16 de Mayo de 1998), Madrid, 1999, pp. 83-92.

BARBu, N. I., Les procédés de la peinture des caractères et la vérité historique dans les Biographies de Plutarque, París, 1933.

Duff, T. E., Plutarch's Lives. Exploring Virtue and Vice, New York, 1999.

Gallardo, M. D., "Estado actual de los estudios sobre los simposios de Platón, Jenofonte y Plutarco," CFC, 3 (1972) 127-92.

Jones, C. P., "Towards a Chronology of Plutarch's Works", JRS, 56 (1966) 61-74.

${ }^{30}$ En contra de la opinión mantenida durante el Congreso por algunos de sus participantes, no existen elementos de juicio que permitan afirmar que las muertes en el banquete siempre se

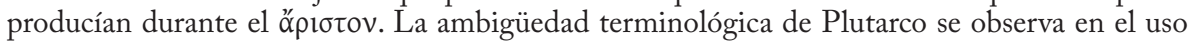
de numerosos y diferentes términos con significado relativamente diferente, pero para referirse a contextos semejantes. A continuación reproducimos el rango de uso de los términos usados por el autor al describir la muerte en banquete: $\delta \varepsilon \tilde{\pi} \pi v o v(10):$ Thes., 30.3, Cat. Mi., 67, Crass., 33.6, Demetr., 36.4 y (ab), 36.11, Pyrrh., 5. 7-14, Ant., 32.3, Pomp., 3.2, Alex., 50.7, Sert., 26.7; пótov

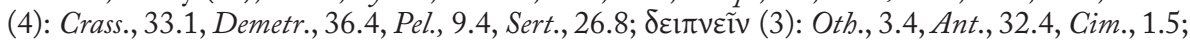

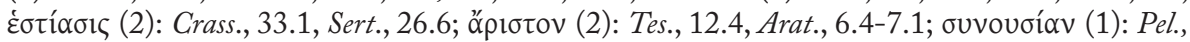

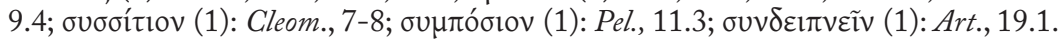

${ }^{31}$ Plu. Lyc., 13, 3. 
Konrad, C. F., Sertorius. A Historical Commentary, Chapel Hill and London, 1994.

Nikolaidis, A. G., "Plutarch's Heroes in Action: Does the End justify the Means?", in I. Gallo, B. Scardigli (eds.), Teoria e Prassi Politica nelle Opere di Plutarco. Atti del V Convegno plutarcheo (Certosa di Pontignano, 7-9 Giugno 1993), Napoli, 1995, pp. 301-312.

PAul, G., "Symposia and Deipna in Plutarch's Lives and Other Historical Writings", in W. J. Slater (ed.), Dining in a classical context, Ann Arbor, 1991, pp. 157-169.

Pelling, Ch., "Is Death the End? Closure in Plutarch's Lives", in D. H. Roberts, D. H. (eds.), Classical Closure. Reading the End in Greek and Latin Literature, Princeton, 1997, pp. 228-250.

Titchener, F.B., "Everything to do with Dionysus: Banquets in Plutarch's Lives", in J. G. Montes Cala et Al. (eds.), Plutarco, Dioniso y el vino. Actas del VI Simposio Español sobre Plutarco (Cádiz, 14-16 de Mayo de 1998), Madrid, 1999, pp. 491-499. 